\title{
Damage Effect of Terrorist Attack Explosion-induced Shock Wave in a Double-deck Island Platform Metro Station
}

\author{
Zihan Liu ${ }^{1,2}$, Nan Jiang $^{1 *}$, Chuanbo Zhou $^{1}$, Lin Ji ${ }^{1}$, Xuedong Luo ${ }^{1}$ \\ ${ }^{1}$ Faculty of Engineering, China University of Geosciences, 430074 Wuhan, China \\ ${ }^{2}$ School of Naval Architecture, Ocean and Civil Engineering, Shanghai Jiao Tong University, 200240 Shanghai, China \\ * Corresponding author, e-mail: jiangnan@cug.edu.cn
}

Received: 27 July 2020, Accepted: 27 September 2020, Published online: 30 October 2020

\begin{abstract}
The objective of this research was to reasonably assess the damage to people and station structures caused by terrorist attack explosion at metro stations, taking the Liyuan station of Wuhan metro which adopts double-deck island platform as an typical example. The TNT explosion process inside the metro station was calculated and analyzed using the dynamic finite element numerical simulation software LS-DYNA. First, the peak overpressure curve and the positive pressure time curve of the shock wave of explosive under the condition of confined space in the metro station were obtained. Then, through the comparison and analysis of the theoretical formulas of explosive shock wave propagation characteristics, the accuracy and reliability of numerical calculation methods and model parameters were verified. At last, combining with the overpressure criterion of shock wave in explosive air, the distribution characteristics of the casualties in the metro station under the explosion shock wave are analyzed, and the dynamic response and damage effect of the pillar structure of the metro station under the explosion shock wave are studied.
\end{abstract}

Keywords

explosion shock wave, metro station, numerical simulation, damage effect, finite element method

\section{Introduction}

In recent years, with the increase in terrorist attacks worldwide, metro stations frequently become the target of explosion attacks. Meanwhile, due to metro stations have a very small fraction of vent openings or free paths to open air, once an explosion occurs within the metro station, it often causes great structural damage and massive casualties. In order to evaluate the impact of terrorist attack explosion on the structure and personnel of metro stations, it is a key issue to analyze the propagation law of explosion shock waves and the structural damage characteristics of metro stations under the impact of explosion shock wave.

As we all know, the shock wave generated by the explosion has a very high nonlinearity, and the duration of its action is relatively short, generally about a few milliseconds [1]. It is very difficult to observe and analyze the deformation and failure process of the structure under the action of explosion load through experimental methods [2]. Moreover, the method of theoretical analysis can only be described in the highly simplified case, and it is difficult to achieve accurate calculation and analysis [3]. In recent years, with the rapid development of computer technology, numerical simulation technology has been widely used in the evaluation of explosion accidents. A large number of scholars have studied the explosion impact damage effect in confined spaces through numerical simulation [4]. For example, Feldgun analyzed the shock wave propagation through the air in the tunnel and discussed the effect of the explosion on a neighboring buried structure [5]. Zhou calculated the propagation characteristic of medium-length hole blasting air wave in a mining tunnel [6]. In the field of explosion pressure flow caused by sudden explosion inside various underground structures, scholars have carried out a large number of experiments and numerical simulation studies. Smith and Mays conducted internal explosion tests on various types of partially-opened cubic caverns and tunnel models made by scale, and obtained overpressure time history curves at different positions inside these structures [7]. Liu investigated the dynamic response and damage of metro structures under internal blast loading by explicit three-dimensional finite element method [8]. Buonsanti and Leonardi studied the behavior of an underground structure subject to the overpressure generated by the blast [9]. 
Meanwhile, there are some scholars who have employed the numerical simulation and model test to study the propagation laws of explosion shock wave inside metro stations, by the way of example, Yan [10] established a coupling "explosive-air-concrete" model and verified the feasibility of the model through experiments. Although the damage assessment of metro station pillars subjected to blast loadings have been obtained, the study on the range of different casualty levels of human body on the platform during the explosion in the metro station have been ignored. Moreover, Pennetier et al. [11] and He et al. [12] proposed a simplified model of overpressure in the metro station to access the dynamic response of the metro station subjected to internal blast loading. However, the verification of the accuracy of above mentioned numerical model needs further study. They not only do not use the relevant theory to verify but also the relevant indoor test methods are not very consistent with the numerical model. What's more, Tan et al. [13] and Sławiński et al. [14] analyzed the influence of blast wave on human body, but they did not consider the impact of shock waves from explosion in metro station on human body, also, this study did not provide a key reference for assessing the damage of metro station structures after the terrorist attack. Ma et al. [15] utilized the Eulerian three-dimensional multi-material parallel hydrocode PMMIC-3D to simulate the attenuation law and pressure-time curve of the shock wave during the explosion in the metro station. This study simply estimated the range of shock waves that may cause harm to human health according to North Atlantic Treaty Organization and the U.S. Department of Defense specifications, which is insufficient. In addition, the study did not analyze the damage to the station structure caused by the explosion shock wave. Therefore, based on the above-mentioned, this work not only employed numerical simulation and a variety of theoretical prediction formulas to verify the accuracy of the numerical model of subway station explosion but also analyzed the weak areas of metro station structure and the damage of shock wave may caused by the explosion to human body.

In this paper, the Liyuan station of Wuhan metro is selected as a case (Fig. 1). The TNT explosion process inside the metro station is calculated with the dynamic finite element numerical simulation software, LS-DYNA, and the attenuation law of the explosion shock wave in the metro station is studied. Based on the verification analysis of the results of theoretical analysis, the damage effect of the shock wave of a terrorist attack explosion in the metro station was studied.

\section{The Liyuan station of Wuhan metro}

There are seven existing metro lines in Wuhan, including Line 1, Line 2, Line 3, Line 4, Line 6, Line 8, and Yangluo Line. The total line length is $237 \mathrm{~km}$, and it ranks 7 th in China. The average daily passenger volume of the Wuhan Metro reaches 2.7 million times, and the highest daily passenger volume reached 3.514 million times. It is the largest transportation hub project in the Central China [16].

Liyuan Station is the terminal station of phase I project of the Wuhan Metro Line 8. It is a typical metro non-transfer station in China, with the two main tracks use left and right parallel settings. The station is set along Wuhan Avenue which is east-west direction. The road width of Wuhan Avenue is about $26 \mathrm{~m}$. The surrounding important buildings are dense, including the Electric Power Economics and Technology Research Institute, Donghu Middle School and Xinhua News Agency Hubei Branch. Because of the constraints of these engineering conditions, Liyuan Station is designed as an underground double-deck island platform station. The first floor underground is the station hall floor, and the second floor underground is the platform floor. The width of the station is $22.5 \mathrm{~m}$, the total length is $180.6 \mathrm{~m}$, and the total construction area of the station is $10187 \mathrm{~m}^{2}$. Its sectional view is shown in Fig. 2. The width of the standard section of the main pit of the station is $25.3 \mathrm{~m}$, and the pit depth is about 25.53 to $25.87 \mathrm{~m}$, the coverage thickness of platform center is about $4.0 \mathrm{~m} \mathrm{[17]} \mathrm{.}$

\section{The numerical simulation model and parameter selection}

The finite element model of the Liyuan station adopts $\mathrm{cm}-\mathrm{g}-\mu \mathrm{s}$ unit system. According to the symmetry of the station, a one-quarter scale model was established. The size

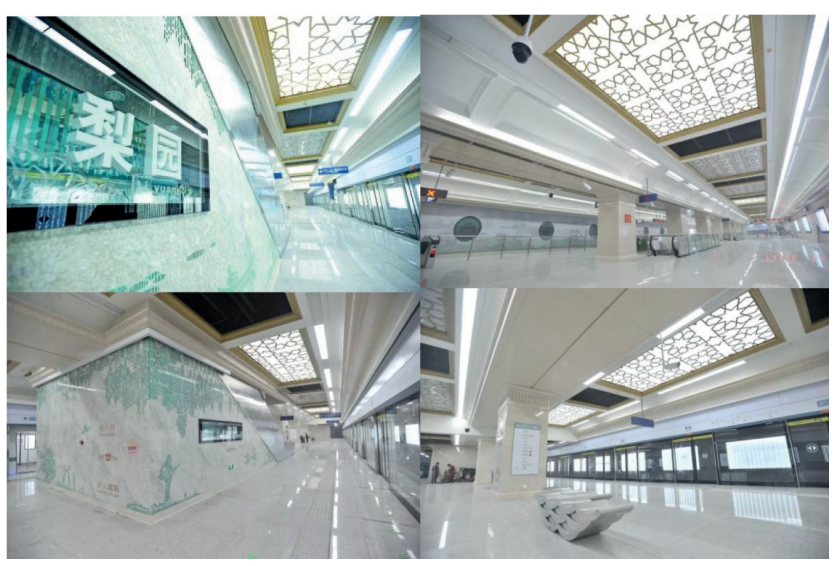

Fig. 1 The interior photo of the Liyuan station 
of the numerical simulation model is $4500 \mathrm{~cm} \times$ $1125 \mathrm{~cm} \times 2030 \mathrm{~cm}$, in which, the cover soil thickness is $400 \mathrm{~cm}$, and the rest of the dimensions are determined by the actual size of the metro station which is shown in Fig. 2. Considering the large size of the stairwell, when an explosion occurs in the metro station, the explosion shock wave may propagate through the stairwell to the station hall floor. Therefore, the stairwell was modeled between No. 1 pillar and No. 2 pillar, its size is $60 \mathrm{~cm} \times 30 \mathrm{~cm}$. The staircase structure is simplified. The finite element model is shown in Fig. 3. Based on the grid convergence analysis, it is determined that the grid size in the vicinity of the explosive is $5 \mathrm{~cm}$, and the grid on far-field is gradually sparse. The entire model is divided into 2,061,299 elements and 2,033,566 nodes.

Both the boundary surface of the positive $X$ direction and the positive $\mathrm{Z}$ direction use symmetry constraints. The free boundary is set on the boundary surface of positive $\mathrm{Y}$ direction. In order to narrow the study area and

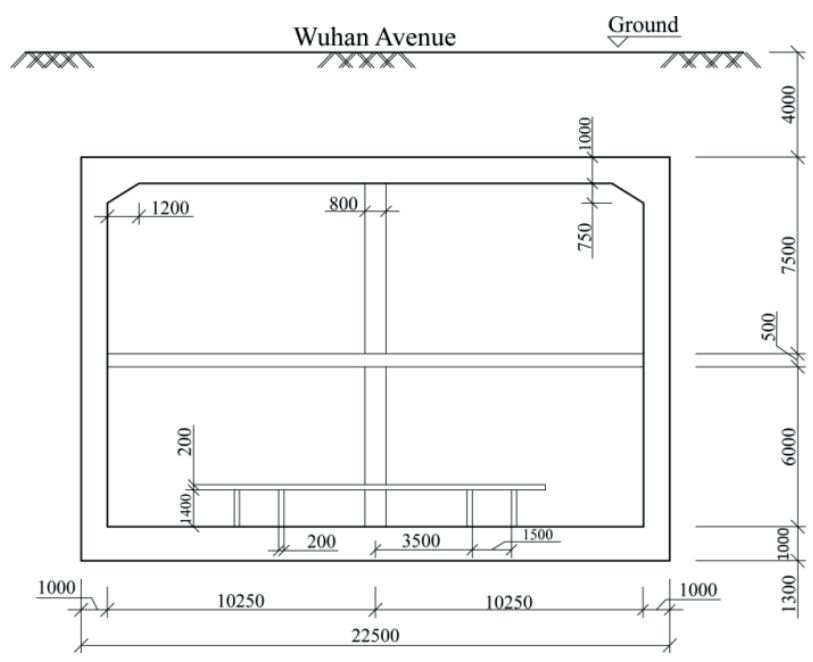

Fig. 2 The cross section of LiYuan station (unit: mm)

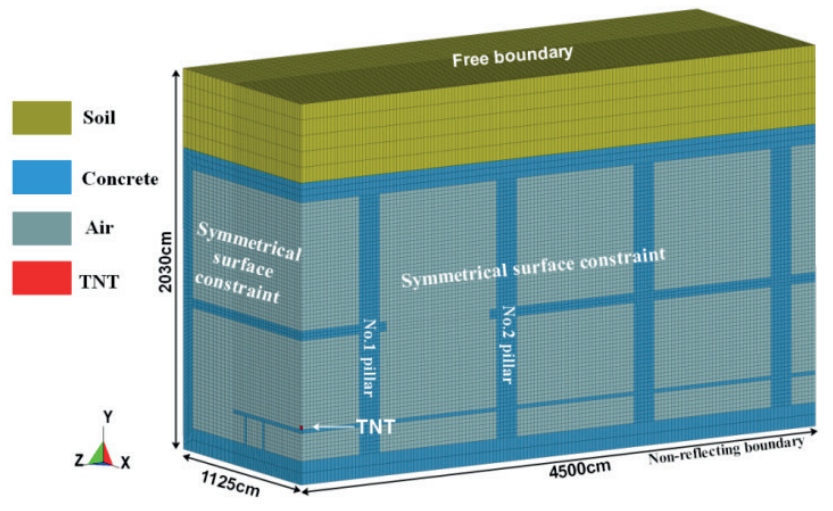

Fig. 3 The finite element model of the metro station ensure calculation accuracy, the non-reflecting boundary is set on the boundary surface of negative $\mathrm{X}$ direction, negative $\mathrm{Z}$ direction and negative $\mathrm{Y}$ direction of the model to simulate an infinite environment [18] .

Material library of LS-DYNA contains many material models for simulating concrete [19]. Tu et al. [20] found that in these concrete models, MAT_CONCRETE DAMAGE can most effectively simulate the mechanical behavior of reinforced concrete under large deformation and high strain rate. At the same time, the model can accurately simulate the dynamic mechanical behavior of reinforced concrete under large deformation and high strain rate by setting the reinforcement ratio of steel bars and avoiding the modeling of steel bars and concrete separately. Therefore, the MAT_CONCRETE_DAMAGE material model was used to model the reinforced concrete structure in this study.

The concrete elements are adopted for pillars, side walls and platform slabs. The space of station is filled with air elements. The explosive and air elements adopt the ALE (Arbitrary Lagrange-Euler) algorithm; the concrete and soil elements adopt the Lagrange algorithm. The fluid-solid coupling algorithm for concrete, air and explosive elements is set via the "*CONSTRAINED_LAGRANGE_ IN_SOLID" keyword.

Since the No. 2 rock emulsion explosive and detonators is relatively easy to obtain in engineering construction, the No. 2 rock emulsion explosive and detonators may be stolen by criminals and brought into the metro station. Since the channel size of baggage security inspection equipment (Fig. 4(a)) in the metro station is generally $650 \mathrm{~mm} \times 500 \mathrm{~mm}$, it is difficult to carry a large amount of explosives pass security inspection. The common 4\# express box is about $350 \mathrm{~mm} \times 190 \mathrm{~mm} \times 230 \mathrm{~mm}$ in size (Fig. 4(b)), which can be put into security inspection channel. It can be assumed that the criminals filled the $4 \#$ express box with No. 2 rock emulsion explosive and managed to pass the security inspection. The density of No. 2 rock emulsion explosive is $1.12 \mathrm{~g} / \mathrm{cm}^{3}$, so it takes $17.50 \mathrm{~kg}$ of explosive to fill the box.

The calculation model of No. 2 rock emulsion explosive is not completed, but the calculation model of TNT are relatively well accepted, therefore, using TNT instead of No. 2 rock emulsion explosive in the finite element model. The weight of TNT is determined by the method of equivalent conversion. The empirical formula of equivalent conversion provided in TM5-1300 [21] is as following: 


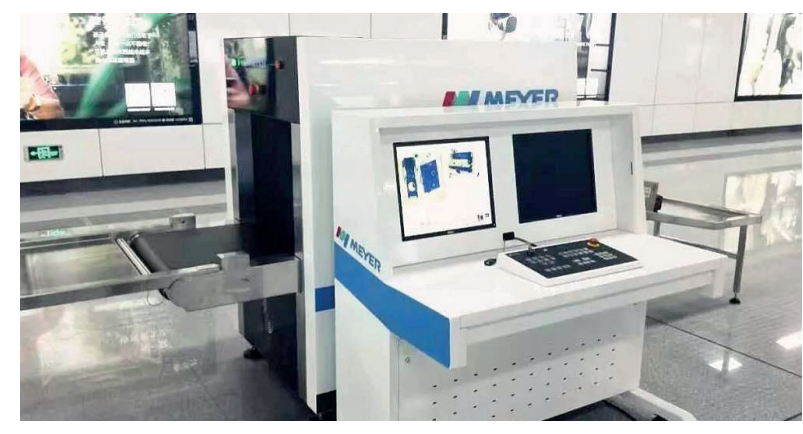

(a)

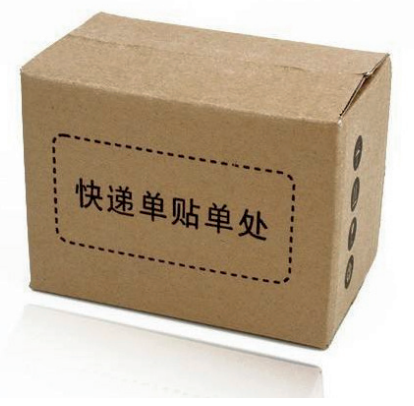

(b)

Fig. 4 Security inspection machine of metro stations and $4 \#$ express box (a) Metro security inspection machine, (b) 4 \# express box

$W_{e}=\frac{E_{\exp }}{E_{T N T}} W_{\exp }$,

where $W_{e}$ is the equivalent charge weight. $W_{\exp }$ is the weight of the explosive in question. $E_{\exp }$ is the energy of detonation of explosive in question. $E_{T N T}$ is the energy of detonation of TNT.

The unit energy of TNT is $4.2 \mathrm{MJ} / \mathrm{kg}$, and the density of TNT is $1.63 \mathrm{~g} / \mathrm{cm}^{3}$ [22]. The unit energy of No. 2 rock emulsion explosive is $3.129 \mathrm{MJ} / \mathrm{kg}$. According to the empirical formula of explosive equivalent conversion, $17.50 \mathrm{~kg}$ of No. 2 rock emulsion explosive is equivalent to $13.04 \mathrm{~kg}$ of TNT (Table 1).

The TNT elements using the cubic charging method, and the size of TNT is $20 \mathrm{~cm} \times 20 \mathrm{~cm} \times 20 \mathrm{~cm}$. Due to the calculation conditions and time constraints, it is difficult to analyze the inner explosion flow field under various conditions, therefore, only representative explosion location can be selected for research. Considering the

Table 1 Parameters of explosive

\begin{tabular}{lccc}
\hline Category & $\begin{array}{c}\text { Density } \\
\left(\mathrm{g} / \mathrm{cm}^{3}\right)\end{array}$ & $\begin{array}{c}\text { Energy } \\
(\mathrm{MJ} / \mathrm{kg})\end{array}$ & $\begin{array}{c}\text { Total weight } \\
(\mathrm{kg})\end{array}$ \\
\hline $\begin{array}{l}\text { No.2 rock emulsion } \\
\text { explosive }\end{array}$ & 1.12 & 3.129 & 17.50 \\
TNT & 1.63 & 4.2 & 13.04 \\
\hline
\end{tabular}

structural symmetry, the explosion point is placed at the center of the platform slab of the metro station. So, the TNT is placed on the platform slab at a distance of $3.3 \mathrm{~m}$ from No. 1 pillar. Set the explosion height to about $0.1 \mathrm{~m}$ above the platform and detonate from the charge center. The total calculation time is $300 \mathrm{~ms}$. Since symmetric boundary conditions are set on the symmetry boundary planes (XY plane and YZ plane) of the finite element model, only one quarter scale model of the TNT is established. The partial structure of the metro station model after placing TNT is shown in Fig. 5.

The main parameters, state equations, and strength models of the materials used in the finite element model are shown in Table 2 to Table 5.

The Jones-Wilkins-Lee (JWL) equation of state is used to simulate the relationship between specific volume and pressure during explosive detonation:

$$
p=A\left(1-\frac{\omega}{R_{1} V}\right) e^{-R_{1} V}+B\left(1-\frac{\omega}{R_{2} V}\right) e^{-R_{2} V}+\frac{\omega E_{0}}{V},
$$

where, $p$ is pressure. A, $B, R 1, R 2$, and $\omega$ are material constants. $V$ is the relative volume. $E_{0}$ is the initial specific internal energy.

The air material in the finite element model uses the *MAT_NULL material model and the equation of state *EOS_LINEAR_POLYNOMIAL. The expression is:

$p=C_{0}+C_{1} \mu+C_{2} \mu^{2}+C_{3} \mu^{3}+\left(C_{4}+C_{5} \mu+C_{6} \mu^{2}\right) E$,

where, $C$ is the material constant. $E$ is the specific internal energy, $0.25 \mathrm{~J} \cdot \mathrm{m}^{-3} \cdot \mu$ is the specific energy.

\section{Verification of propagation characteristic of explosion shock wave}

To simulate the stress characteristics of the metro station structure under the explosive effect of explosives, the key is to select the calculation model that fits the blast load. In order to ensure the validity of the calculation model, the

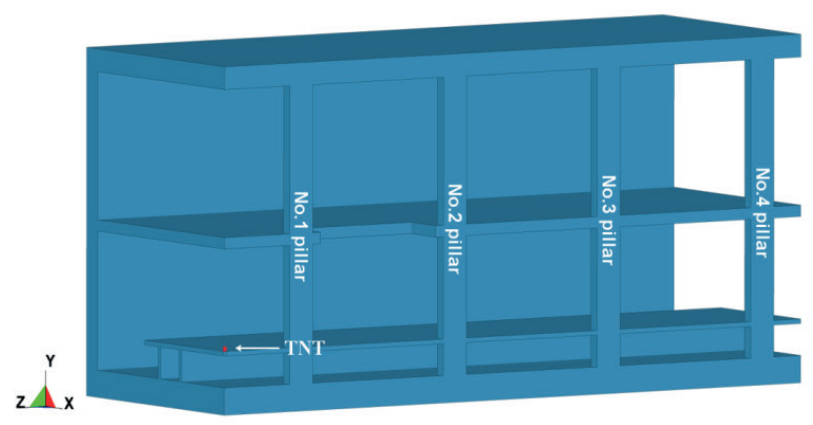

Fig. 5 The location of the explosives in the metro station 
numerical simulation result is compared with the theoretical formula results to verify the reliability of the numerical simulation method and the finite element model. Table 6 lists the details of each monitoring point.

Peak overpressure is the main influencing factor of the impact of explosion shock wave on peripheral objects, so the accurate calculation of peak overpressure is the key of numerical simulation. In order to ensure the authenticity of the explosion shock wave in numerical simulation and the accuracy of the calculation results, the numerical simulation results are compared with the calculated results of the commonly used theoretical formulas of overpressure [24] .The relative theoretical formulas which describe the relationship between the peak overpressure and the scaled-distance are as follows:

According to the Henrych formula [25],

$$
\Delta P_{f}= \begin{cases}\frac{1.40717}{\bar{R}}+\frac{0.55397}{\bar{R}^{2}}-\frac{0.03572}{\bar{R}^{3}}+\frac{0.000625}{\bar{R}^{4}} & 0.05 \leq \bar{R}<0.3 \\ \frac{0.61938}{\bar{R}}-\frac{0.03262}{\bar{R}^{2}}+\frac{0.21324}{\bar{R}^{3}} & 0.3 \leq \bar{R}<1.0, \\ \frac{0.0662}{\bar{R}}+\frac{0.405}{\bar{R}^{2}}+\frac{0.3288}{\bar{R}^{3}} & 1.0 \leq \bar{R} \leq 10.0\end{cases}
$$

where, $\Delta P_{f}$ is the peak overpressure of the shock wave (MPa). $\bar{R}=\frac{R}{\sqrt[3]{W}}$ is the scaled-distance. $R$ is the distance from the detonation center $(\mathrm{m}) . W$ is equivalent TNT weight $(\mathrm{kg}) . t$ is positive pressure time (s).

According to Sadovskii formula [26],

$\Delta p_{f}=\left\{\begin{array}{ll}\frac{1.07}{\bar{R}^{3}}-0.1 & \bar{R} \leq 1.0 \\ \frac{0.076}{\bar{R}}+\frac{0.255}{\bar{R}^{2}}+\frac{0.65}{\bar{R}^{3}} & 1.0<\bar{R} \leq 15\end{array}\right.$,

According to Brode formula [27],

$\Delta p_{f}=\left\{\begin{array}{ll}\frac{0.657}{\bar{R}^{3}}+0.098 & \bar{R}>0.98 \\ \frac{0.096}{\bar{R}}+\frac{0.143}{\bar{R}^{2}}+\frac{0.573}{\bar{R}^{3}}-0.0019 & 0.0098 \leq \bar{R} \leq 0.98\end{array}\right.$.

It can be seen from Fig. 6(a), when scaled-distance is less than $1.0 \mathrm{~m} / \mathrm{kg}^{1 / 3}$, the curve of numerical simulation are in good agreement with the general variation trend of the curves of theoretical formulas and are the closest to the curve of Brode formula. With the increase of the scaled-distance, the difference between the curve of numerical simulation and the curves of theoretical formulas is decreased.

Table 2 Material model and EOS parameters of TNT

\begin{tabular}{lccccc}
\hline Material & Density $\left(\mathrm{g} / \mathrm{cm}^{3}\right)$ & Detonation velocity(cm/us) & CJ pressure(MPa) & Beta burn flag & EOS \\
\hline TNT & 1.63 & 1.6 & 0.7 & 0.255 & JWL \\
\hline
\end{tabular}

Table 3 Material model and EOS parameters of air

\begin{tabular}{lcccccccccc}
\hline Material & Density $\left(\mathrm{g} / \mathrm{cm}^{3}\right)$ & $\mathrm{C}_{0}$ & $\mathrm{C}_{1}$ & $\mathrm{C}_{2}$ & $\mathrm{C}_{3}$ & $\mathrm{C}_{4}$ & $\mathrm{C}_{5}$ & $\mathrm{C}_{6}$ & $\mathrm{EOS}$ \\
\hline Air & $1.225 \times 10-3$ & 0 & 0 & 0 & 0 & 0.4 & 0.4 & 0 & EOS_LINEAR_POLYNOMIAL \\
\hline
\end{tabular}

Table 4 Material model and EOS parameters of soil

\begin{tabular}{lcccccr}
\hline Material & $\begin{array}{c}\text { Density } \\
\left(\mathrm{g} / \mathrm{cm}^{3}\right)\end{array}$ & Poisson's ratio & $\begin{array}{c}\text { Shear modulus } \\
(\mathrm{MPa})\end{array}$ & $\begin{array}{c}\text { Elastic } \\
\text { modulus }(\mathrm{MPa})\end{array}$ & $\begin{array}{c}\text { Cohesion } \\
(\mathrm{MPa})\end{array}$ & Frictional angle $\left(^{\circ}\right)$ \\
\hline Soil & 1.80 & 0.32 & 3.85 & 30.0 & 0.06 & EOS \\
\hline
\end{tabular}

Table 5 Material model and EOS parameters of concrete [23]

\begin{tabular}{ccccccc}
\hline Material & $\begin{array}{c}\text { Density } \\
\left(\mathrm{g} / \mathrm{cm}^{3}\right)\end{array}$ & $\begin{array}{c}\text { Poisson's } \\
\text { ratio }\end{array}$ & $\begin{array}{c}\text { Shear modulus } \\
(\mathrm{MPa})\end{array}$ & $\begin{array}{c}\text { Elastic modulus } \\
(\mathrm{MPa})\end{array}$ & $\begin{array}{c}\text { Compressive } \\
\text { strength }(\mathrm{MPa})\end{array}$ & $\begin{array}{c}\text { Strength } \\
\text { model }\end{array}$ \\
\hline Concrete & 2.60 & 0.2 & $18.91 \times 103$ & $2.0 \times 104$ & 36.4 & CONCRETE_DAMAGE \\
\hline
\end{tabular}

Table 6 Location of monitoring points

\begin{tabular}{|c|c|c|c|c|c|c|c|}
\hline Monitoring point ID & H67125 & H68025 & H69852 & H70125 & H71569 & H72669 & H80025 \\
\hline Multiples of $\bar{R}$ & 0.5 & 0.6 & 0.7 & 0.8 & 0.9 & 1 & 1.5 \\
\hline Distance from explosive source(m) & 1.18 & 1.42 & 1.66 & 1.89 & 2.13 & 2.37 & 3.55 \\
\hline Monitoring point ID & H83215 & H87250 & H90258 & H99563 & H112565 & H135691 & H128753 \\
\hline Multiples of $\bar{R}$ & 2 & 2.5 & 3 & 3.5 & 4 & 4.5 & 5 \\
\hline Distance from explosive source(m) & 4.73 & 5.91 & 7.09 & 8.28 & 9.46 & 10.64 & 11.83 \\
\hline
\end{tabular}


As shown in Fig. 6(b), when scaled-distance is greater than $1.0 \mathrm{~m} / \mathrm{kg}^{1 / 3}$, the general trend of these curves is very close, and the difference between the curve of numerical simulation and the curves of theoretical formulas are very small. The above conclusions show that the overpressure of shock wave in the finite element model has certain reliability.

The positive phase time is another significant factor to study the characteristic of explosion shock wave. The positive phase time results of the numerical simulation and the theoretical formulas are compared, and the comparison result are shown in Fig. 7.

The commonly used positive pressure time theoretical formulas are as follows:

$t_{+}$is the positive phase time of shock wave. According to Henrych formula [25],

$$
\begin{aligned}
\frac{t_{+}}{\sqrt[3]{m}} & =10^{-3}\left(0.107+0.444 \bar{R}+0.264 \bar{R}^{2}-0.129 \bar{R}^{3}\right. \\
& +0.0335 \bar{R}^{4}, 0.05 \leq \bar{R} \leq 3
\end{aligned}
$$

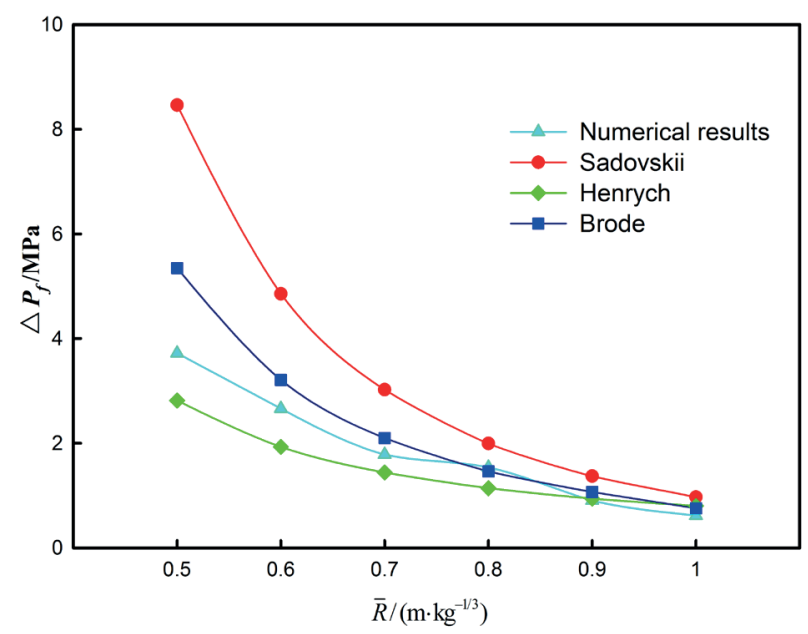

(a)

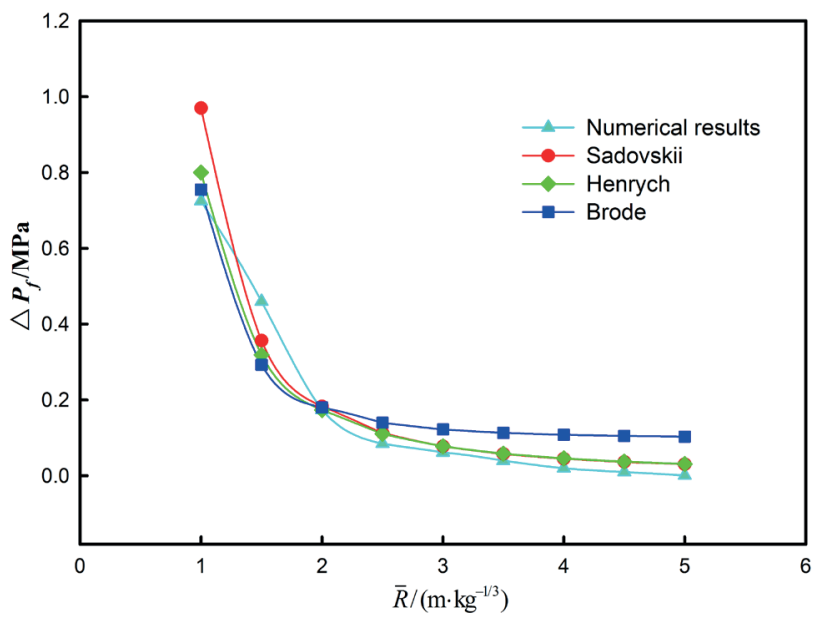

(b)

Fig. 6 The curve derived from numerical calculation and theoretical formulas (a) $\bar{R}$ is $0.5-1.0 \mathrm{~m} / \mathrm{kg}^{1 / 3}$, (b) $\bar{R}$ is $1.0-5.0 \mathrm{~m} / \mathrm{kg}^{1 / 3}$
According to Sadovskii formula [26],

$t_{+}=1.35 \times 10^{-3} \sqrt[3]{m} \sqrt{\bar{R}}$.

As shown in Fig. 7, from the overall trend, the positive phase time of explosion shock wave of the numerical simulation result is close to the Henrych formula result. The two curves are nearly parallel, but the positive pressure phase time of the numerical simulation result is always slightly larger than the Henrych formula, and the deference is within the acceptable range.

The Pearson correlation coefficient is a tool used to reflect the degree of linear correlation between two variables. In this paper, the Pearson correlation coefficient is used to investigate the relationship between the numerical simulation results and the theoretical formula results [28]. The correlation coefficient is calculated according to Eq. (9).

$r_{x y}=\frac{\sum_{i=1}^{n}\left(x_{i}-\bar{x}\right)\left(y_{i}-\bar{y}\right)}{\sqrt{\sum_{i=1}^{n}\left(x_{i}-\bar{x}\right)^{2} \sum_{i=1}^{n}\left(y_{i}-\bar{y}\right)^{2}}}$,

where, $\left\{x_{i}, i=1,2, \ldots, n\right\}$ and $\left\{y_{i}, i=1,2, \ldots, n\right\}$ are two sets of sequences of length $n$, respectively.

The correlation between the two variables can be determined initially by the correlation coefficient, but the significance test must be performed before final judgment [28]. The significance test formula is:

$t=\frac{\left|r_{x y}\right|}{\sqrt{\left(1-r_{x y}{ }^{2}\right)} /(n-2)}$

In order to further analyze the relationship between numerical simulation results and theoretical formulas results, their calculation results are input into SPSS statistical analysis

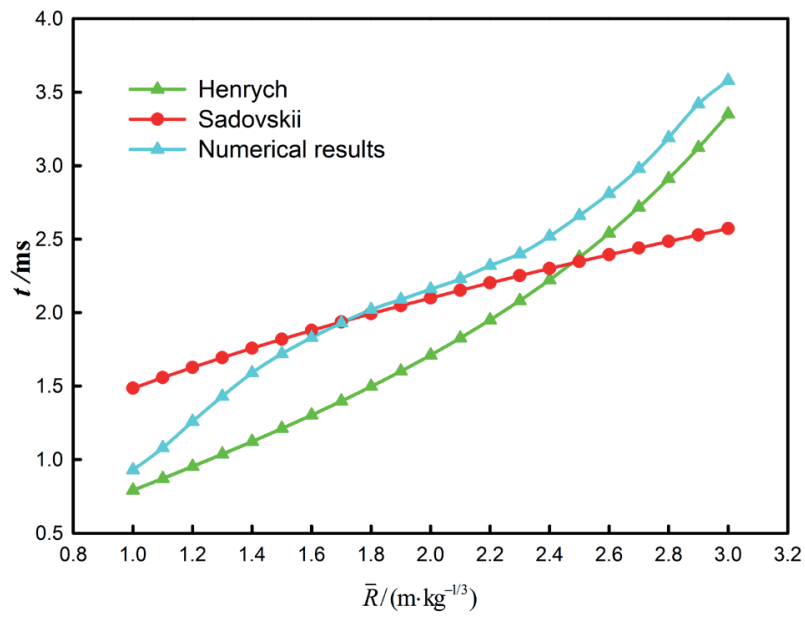

Fig. 7 Comparison of positive phase time 
software for correlation analysis (Table 7). In the comparison of the calculation result of the positive phase time, the Pearson correlation coefficients between the numerical simulation and the Henrych formula and the Sadovskii formula are 0.989 and 0.925 , respectively. In the comparison of the calculation result of peak overpressure, the Pearson correlation coefficients between numerical simulation and Henrych formula, Sdovskyi formula and Brode formula are $0.978,0.992$, and 0.996 respectively. According to the probabilistic and statistical laws, it can be considered that the numerical simulation results and the theoretical formula calculation results are significantly correlated at the 0.01 level (both sides) in these two comparisons, showing the reliability of the finite element model.

Based on the above comparison and analysis of numerical simulation result and theoretical calculation results, it can be considered that the finite element model and numerical simulation method have high reliability, so when the explosion occurred in the metro station, because the field test does not have the feasibility and economy, so choose the method of numerical simulation to analyze. The results of the following analysis are based on the finite element model established in this case.

\section{Damage effect of explosion shock wave in metro station 5.1 The killing effect of explosion shock wave on human body}

Due to the limitation of experimental conditions, there is no relevant experiment of the explosion in the metro station, and no relevant theories and experimental studies have been carried out on the casualties of terrorist attacks in the metro station. In this paper, the numerical simulation method is used to predict the area of casualties when an explosion occurred in the metro station.

The main cause of injury to personnel is the explosion shock wave. Persons who are close to the explosion source often cause death due to the high overpressure of the explosive shock wave in the near-field explosion. In addition, lungs, eardrums, and other parts of people who are relatively far from the explosion source are also vulnerable because explosive shock wave still has a certain intensity.

At present, the criteria for damage assessment of explosion shock wave include overpressure criteria, impulse criteria and overpressure-impulse criteria. Due to the wide scope of application of the overpressure criteria, it is a criteria adopted by most scholars [29]. The overpressure criteria, that is, whether the explosion shock wave causes damage to the target is only determined by the overpressure peak [30]. When the peak overpressure of the explosion shock wave exceeds a certain critical value, namely the overpressure threshold, the explosion shock wave will cause damage to the target.

Based on a large number of animal experiments, Zheng [31] also summarized the relevant standards of the United States, the Soviet Union, etc., and referenced the human casualties of major explosion accidents worldwide, and provided the corresponding overpressure thresholds for different injury levels (Table 8). Compared with relevant research conclusions [32], the thresholds are not much different. Therefore, this study intends to use the overpressure thresholds as an evaluation standard for assessing the casualties caused by explosions in metro stations.

Peak overpressure is the main indicator of casualties. In order to calculate the peak overpressure in each area on the platform slab, dense monitoring points are set at the ear level, i.e., at about $1.5 \mathrm{~m}$, on the platform slab of the numerical model. The layout of the monitoring points is shown in Fig. 8. The distance between the monitoring points is $1 \mathrm{~m}$, and a total of 330 monitoring points are set.

In accordance with the overpressure threshold corresponding to different casualty levels given by Zheng [31], the peak overpressure at each monitoring point in the numerical model is distinguished. According to different casualty levels (slight injury, medium injury, severe injury, death), the area of casualty on the platform slab is divided. Each color representing a casualty level, and the result of the division is shown in Fig. 9.

Table 7 Correlation analysis of numerical calculation results and theoretical formulas results

\begin{tabular}{lcc}
\hline Category & $\begin{array}{c}\text { Pearson correlation } \\
\text { of shock wave peak } \\
\text { overpressure }\end{array}$ & $\begin{array}{c}\text { Pearson correlation of } \\
\text { positive pressure time }\end{array}$ \\
\hline J. Henrych & 0.978 & 0.989 \\
M. A. Sadovskii & 0.992 & 0.925 \\
Brode & 0.996 & $/$ \\
\hline
\end{tabular}

Table 8 Comparison of different overpressure criteria [31] (Unit: kPa)

\begin{tabular}{lcccc}
\hline Unit: kPa & $\begin{array}{c}\text { Slight } \\
\text { Injury }\end{array}$ & $\begin{array}{c}\text { Medium } \\
\text { Injury }\end{array}$ & Severe Injury & Death \\
\hline United States & 15.69 & 23.54 & 53.94 & $\geq 186.33$ \\
Soviet Union & $19.61 \sim 39.23$ & $/$ & $39.23 \sim 98.07$ & $\geq 235.37$ \\
$\begin{array}{l}\text { Explosion } \\
\text { Accident }\end{array}$ & $10.79 \sim 27.46$ & $27.46 \sim 49.04$ & $49.04 \sim 127.49$ & $\geq 127.49$ \\
$\begin{array}{l}\text { Animal } \\
\text { Experiment }\end{array}$ & $9.81 \sim 19.61$ & $19.61 \sim 39.23$ & $39.23 \sim 58.84$ & $\geq 58.84$ \\
Zheng [31] & 13.73 & 29.43 & 49.05 & $\geq 127.49$ \\
\hline
\end{tabular}




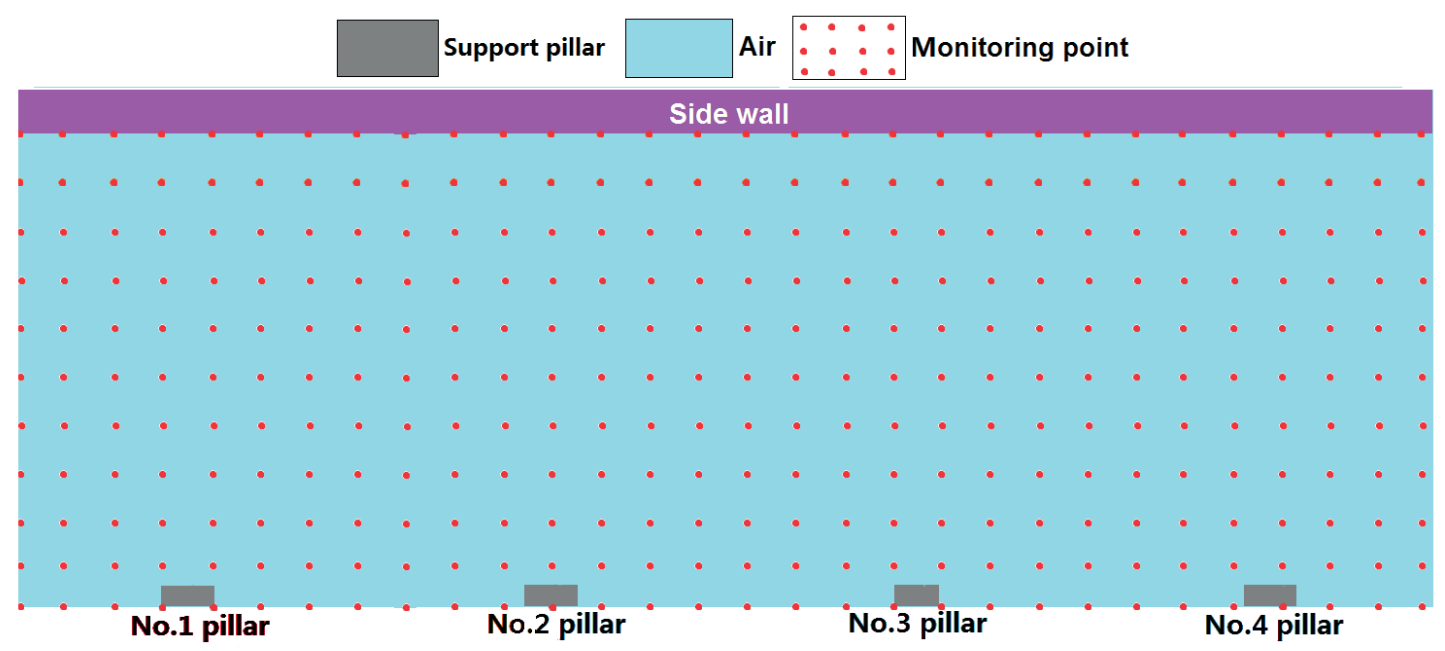

Fig. 8 Layout of monitoring points

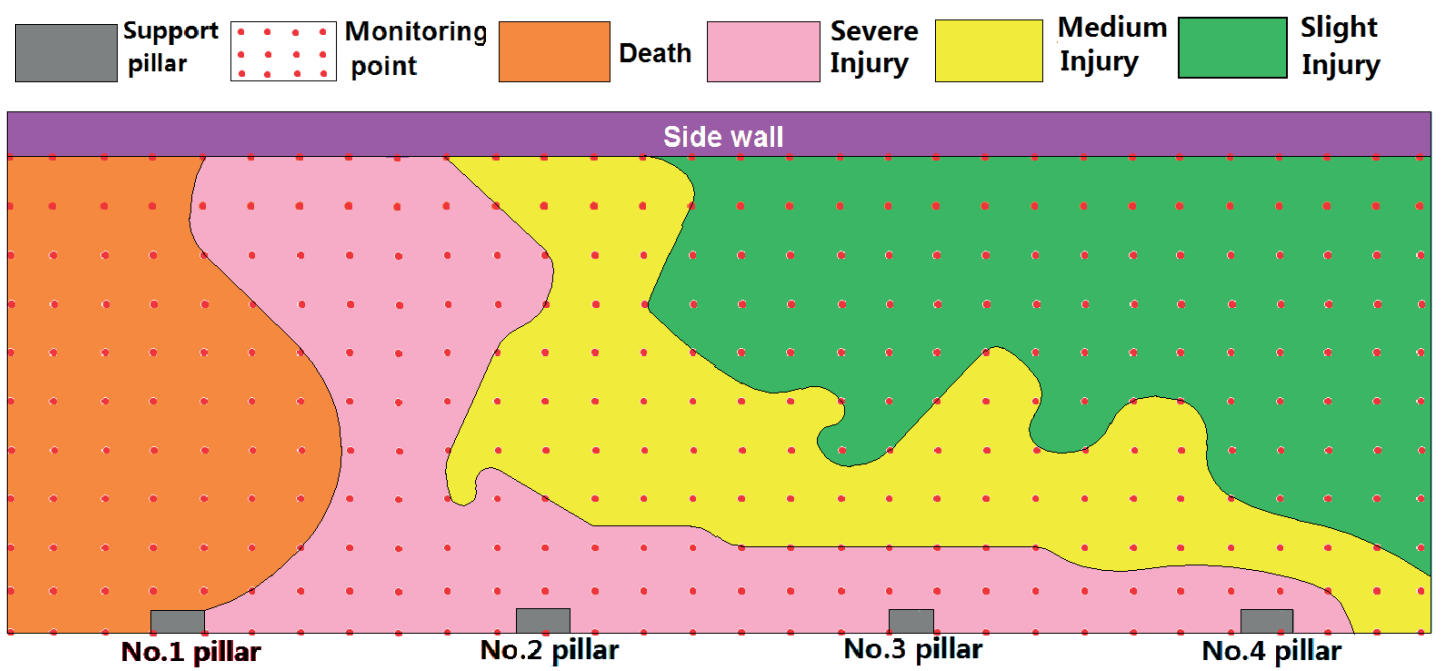

Fig. 9 Distribution of human casualties under the influence of $13.23 \mathrm{~kg}$ TNT

It can be seen from Fig. 9 that the distribution of shock waves on the platform slab is complicated due to the influence of structural shape, pillar position, and other factors. The division of casualties in the area is irregular, but the casualty area is generally spread as "radiation diffusion" centered on the explosive source, the farther away from the explosive source, the smaller the damage, which is in line with the propagation law of the explosion shock wave. The damage near the surface of the pillar that facing the explosive is relatively large, and the degree of damage near the surface of the pillar that facing away from the explosive is relatively small. It can be considered that the pillar has a certain shielding effect on the shock wave. Based on the human casualty distribution (Fig. 9), it can be concluded that under the influence of $13.23 \mathrm{~kg}$ of TNT, the distance to death is approximately $7 \mathrm{~m}$ (radius centered on the explosion source).

\subsection{The damage effect of explosive shock wave on the pillar}

From the calculation results, we can find that the peak stress of the metro station structure appears $70 \mathrm{~ms}$ after the explosive initiation, and the stress contour of the metro station structure is obtained at this time, which can reflect the overall impact of explosion shock wave on the metro station structure (Fig. 10).

Reinforced concrete pillars are generally used as loadbearing frame pillars in important structures. Their antiexplosion ability is directly related to whether the entire structure will collapse continuously due to the failure of the pillar. As can be seen from Fig. 10, the explosion shock wave has the greatest impact on the No. 1 pillar closest to the explosive source. The peak stress on the No. 1 pillar appears at the junction of the pillar and the platform slab on the 2nd floor underground, reaching 70.4 MPa. However, 


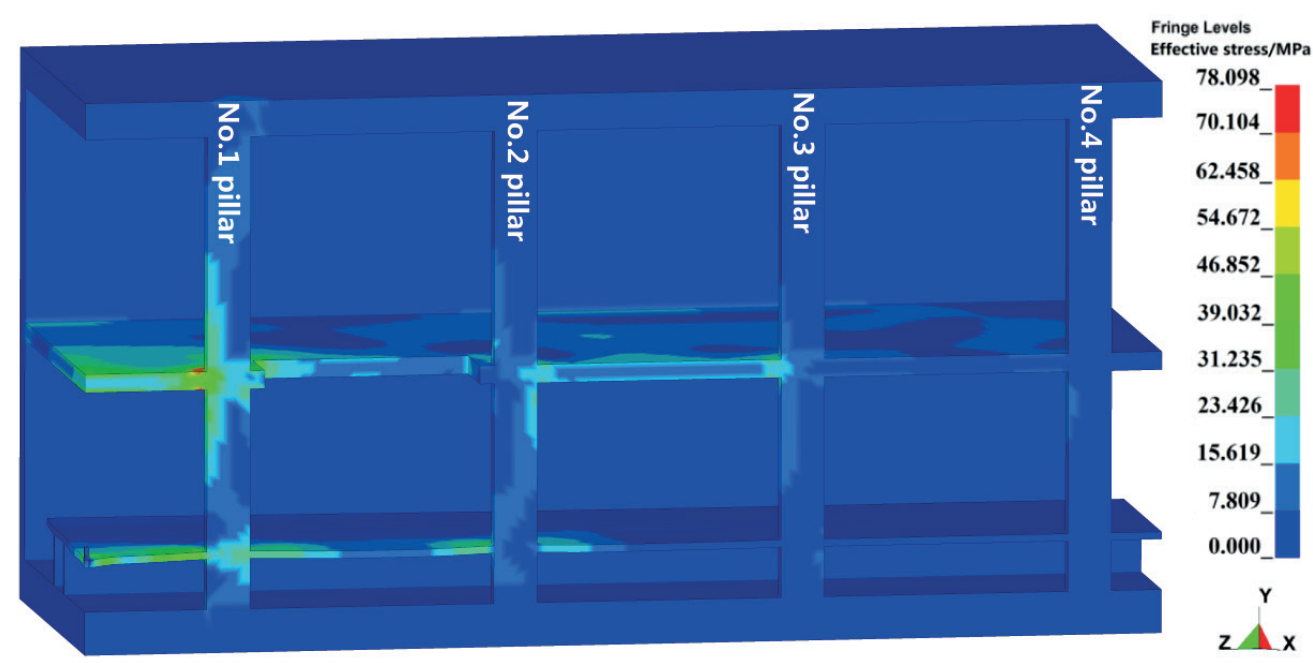

Fig. 10 Stress contour of the metro station structure

the impact on the No. 2 pillar far away from the explosive source is relatively small, and the stress peak on the No. 2 pillar also appears at the junction of the pillar and the platform slab on the 2 nd floor, reaching $21.3 \mathrm{MPa}$. The stress peaks on the No. 3 pillar and the No.4 pillar are much lower than those on the No. 1 pillar, which are 9.6 $\mathrm{MPa}$ and 3.1 MPa, respectively. It can be seen that the explosion shock wave only has a large damage effect on the partial area, which is in line with the general law of explosion.

Because the explosive response on No. 1 pillar is obviously stronger than No. 2, 3, and 4 pillars far from explosive, it is representative. Therefore, only the No. 1 pillar is taken as the research object in the following analysis of the pillar response, no more repeated analysis of No. 2, 3, and 4 pillars.

This section mainly analyzes the structural response characteristics of the No. 1 pillar when an explosion occurs in the metro station. The distribution of monitoring points on the pillar is shown in Fig. 11. In the figure, the A-surface is the surface facing the explosive, the $\mathrm{B}$-surface is the right side of the pillar, and the $\mathrm{C}$-surface is the surface that facing away from the explosive. Line-A, line-B and line-C are the symmetry axes of the A, B and $\mathrm{C}$ surfaces of the pillar in the vertical direction. Line-L and line-M are on the corners of the pillar. The pillar is divided into upper, middle and lower sections with floor as the boundary. The highest point, lowest point and middle point on the five typical lines of each section are selected as monitoring points. A total of 9 monitoring points are selected for each typical line, numbered 1 to 9 in sequence.

The stress state of reinforced concrete pillars under blast loading is complex, and it is an important method to reflect the stress characteristics using Mises stress. Mises stress is an equivalent stress. When the equivalent stress is used for simple judgment, the large equivalent stress value indicates that the stress state at this area is not ideal, and it is often the area where the material is easily damaged, and also the area where the material deformation is large. Table 9 shows the peak Mises stress of monitoring points on the typical lines of the pillar.

It can be seen from the table, since the explosion shock wave is blocked by the surface facing explosive of the pillar, the average Mises stress and peak Mises stress on the $\mathrm{A}, \mathrm{B}$, and $\mathrm{C}$ lines show a decreasing trend. The maximum and average value of monitoring points on Line- $\mathrm{C}$ are the smallest, and do not exceed the strength of concrete, so it's safe. The maximum and average values of the peak Mises stress at each monitoring point of the line- $\mathrm{L}$ are

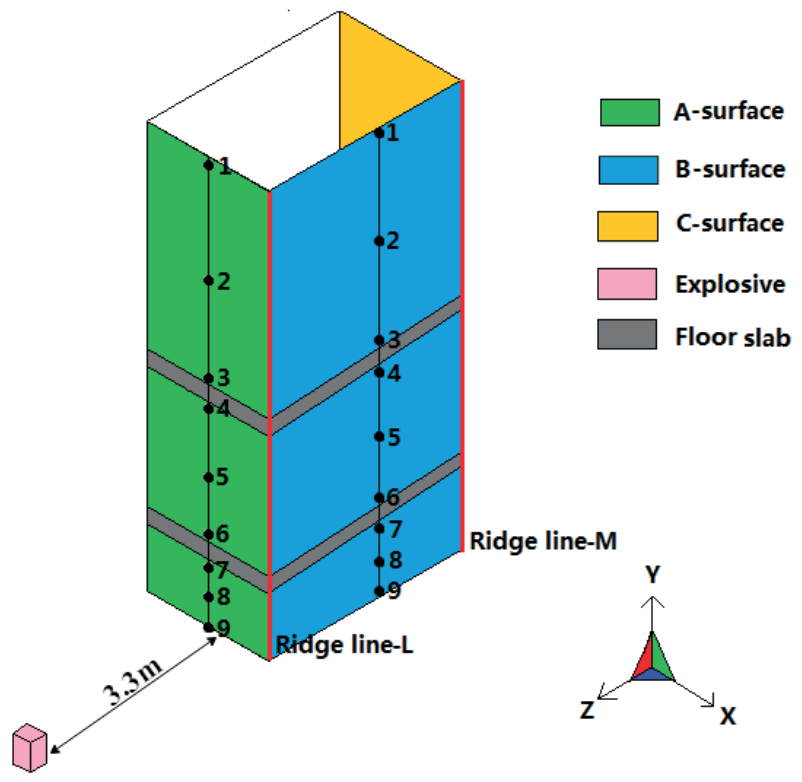

Fig. 11 Distribution of monitoring points 
the largest. The maximum value of the peak Mises stress on the line- $\mathrm{L}$ is 1.93 times higher than that of the line-A. The result shows that the most vulnerable area is not on the closest surface to the explosive source. In the finite element model of this case, the stress on the corner closest to the explosive of the column is the highest. This is mainly because the corner of pillar is a geometrical change point, so stress concentration is often formed, and the explosion shock wave will collide and superimpose here, thereby increasing the damage effect [33] .

In Table 9, the minimum value of the peak Mises stress at each monitoring point is just $2.3 \mathrm{MPa}$, but the maximum value is $25.1 \mathrm{MPa}$. It can be seen that the distribution of stress in each part of the pillar is very uneven. Some parts of the pillar may have cracks or breakages due to high stress values. The distribution of peak Mises stress in the upper, middle and lower sections of the pillar also shows a certain law. The distribution of stress in the middle section of the pillar is large at both ends and small in the middle. However, since the upper and lower sections of the pillar are not directly affected by the explosion shock wave, the stress tends to decrease gradually in these sections.

At present, scholars mainly use the three parameters of shock wave of overpressure, impulse and positive phase time to describe the explosion shock wave. The structural damage caused by the explosion shock wave cannot be evaluated simply by the overpressure or positive phase time, but the impulse combines the two main parameters of the explosion shock wave [34]. The greater the impulse of the explosion load, the greater the accumulation of damage to the structure. The expression of impulse is as in Eq. (11):

$I=\int_{t_{0}}^{0+t_{n}} p(r, t) d t$

where, $r$ is the distance from the explosion to the measuring point. $t_{0}$ is the starting time of the shock wave reaching the measuring point. $t_{n}$ is the positive phase time.

Using the "trapz" function in MATLAB software to perform numerical integration using the trapezoidal method, and the impulse of the monitoring points on the pillar is listed in Table 10.

Both the impulse and the Mises stress are important indicators for measuring the damage degree of the shock wave to the structure. By comparing and analyzing the impulse of the monitoring points on the pillar, it can be found that although the impulse of some monitoring points is small, the peak Mises stress of the monitoring points is relatively large, such as the 5th point on the line- $\mathrm{L}$.
Table 9 Monitoring point Mises stress peak statistics (unit: MPa)

\begin{tabular}{lccccc}
\hline $\begin{array}{l}\text { Monitoring } \\
\text { point } \\
\text { (unit: } \mathrm{MPa})\end{array}$ & A-surface & B-surface & C-surface & line-L & line-M \\
\hline 1 & 3.5 & 2.3 & 2.7 & 4.1 & 2.5 \\
2 & 6.7 & 3.5 & 6.1 & 6.7 & 8.5 \\
3 & 8.2 & 7.6 & 9.9 & 21 & 8.9 \\
4 & 11.8 & 7.9 & 9.2 & 25.1 & 10.9 \\
5 & 8.7 & 4.9 & 5.2 & 9.2 & 5.2 \\
6 & 12.9 & 11.8 & 7.1 & 13.9 & 9.5 \\
7 & 13.0 & 11.8 & 7.1 & 13.9 & 7.2 \\
8 & 4.1 & 5.1 & 5.3 & 4.2 & 5.9 \\
9 & 4.8 & 5.5 & 6.5 & 5.6 & 7.2 \\
Average & 8.2 & 6.7 & 6.6 & 11.5 & 7.3 \\
Maximum & 13.0 & 11.8 & 9.9 & 25.1 & 10.9 \\
\hline
\end{tabular}

Table 10 The impulse of monitoring points (unit: $\mathrm{kPa} \cdot \mathrm{ms}$ )

\begin{tabular}{|c|c|c|c|c|c|}
\hline $\begin{array}{l}\text { Monitoring } \\
\text { point } \\
\text { (unit: } \mathrm{kPa} \cdot \mathrm{ms} \text { ) }\end{array}$ & A-surface & B-surface & C-surface & L-line & M-line \\
\hline 1 & 717.38 & 423.65 & 552.73 & 541.05 & 606.85 \\
\hline 2 & 983.17 & 810.66 & 742.57 & 794.63 & 1113.78 \\
\hline 3 & 991.57 & 458.02 & 670.97 & 662.57 & 782.66 \\
\hline 4 & 803.79 & 512.21 & 447.84 & 254.19 & 594.64 \\
\hline 5 & 933.55 & 774.02 & 850.35 & 1057.98 & 803.79 \\
\hline 6 & 812.94 & 416.78 & 790.81 & 525.94 & 769.44 \\
\hline 7 & 1612.16 & 831.27 & 1064.85 & 1387.74 & 1504.53 \\
\hline 8 & 964.09 & 652.65 & 614.48 & 652.65 & 590.82 \\
\hline 9 & 764.86 & 334.34 & 515.25 & 435.71 & 383.19 \\
\hline Average & 953.06 & 579.29 & 694.54 & 701.38 & 794.41 \\
\hline Maximum & 1612.16 & 831.27 & 1064.85 & 1387.74 & 1504.53 \\
\hline
\end{tabular}

Conversely, some points have a large impulse, but the peak Mises stress at that point is relatively small, such as the 6th point on line-B. This indicates that to investigate the damage degree of the explosion shock wave to the structure, the effects of both Mises stress and impulse should be considered comprehensively.

Because the ends of the pillar of the numerical model are constrained, the displacement of the pillar mainly occurs in the XZ plane of the numerical model. In the XZ plane, the $X$ direction meets the symmetric plane, so the displacement can be ignored. The $\mathrm{Z}$ direction is parallel to the connecting line from the explosion source to the pillar, so it's the dominant propagation direction of the shock wave (Fig. 12), therefore, in the numerical model, the displacement in the $\mathrm{Z}$ direction of the monitoring points in each direction is the largest, which is in accordance with the basic law of explosion shock wave propagation. 
Fig. 13 shows the $\mathrm{Z}$ direction displacement response at each monitoring point. The $\mathrm{Z}$ direction displacement of the monitoring point 2 and 5 on each typical line are relatively large. This is because the displacement of middle part of pillar is the cumulative result at both ends, and the two ends are basically in a fixed state. While the monitoring point 2 and 5 are the middle parts of the upper and middle sections of the pillar respectively, they are far from the fixed end. The $\mathrm{Z}$ direction displacement of each monitoring point on the $\mathrm{L}$ and $\mathrm{M}$ lines are larger than the $\mathrm{A}, \mathrm{B}$, and $\mathrm{C}$ lines, which confirms that the corners of pillar are weak and easily damaged.

\subsection{Pressure-Impulse diagram for the reinforced concrete pillar}

The assessment of the damage degree of the structure under blast loading is a very complicated problem. At present, the pressure-impulse (P-I) curve method is generally accepted and widely used in the engineering field. For a specific structure, the P-I curve for the corresponding damage degree is fixed. When the structure encounters an explosion, determining the overpressure and impulse of the explosion can quickly assess the damage degree of the structure.

In order to determine the damage degree of the structure, specific failure criteria need to be determined experimentally. In general, the maximum ductile deformation of

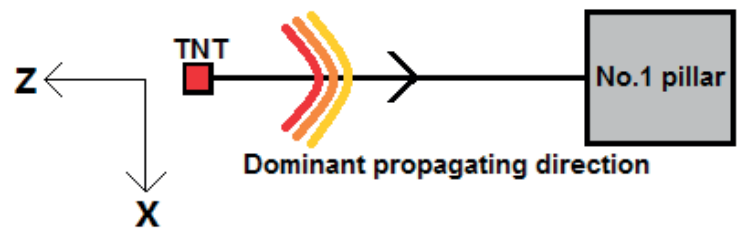

Fig. 12 Shock wave dominant propagating direction

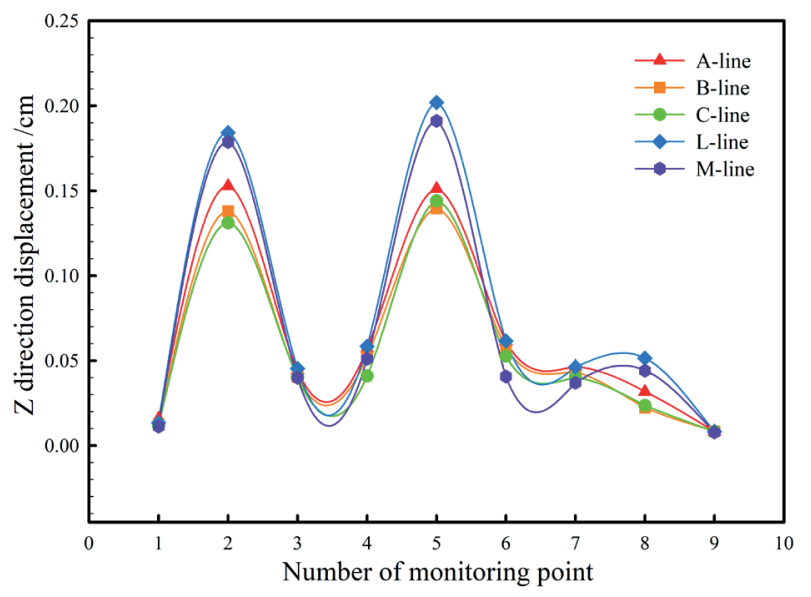

Fig. $13 \mathrm{Z}$ direction displacement peak at each monitoring point a structural member undergoing bending failure usually occurs at the mid-span area of the member. Therefore, the rotation angle of bearing determined by the ratio of the maximum mid-span deflection to the half-span length of the member is generally used as an indicator of the bending failure criteria of the structural member. The failure criteria of reinforced concrete pillar used in this paper is shown in Table 11.

In order to determine the P-I curve of the reinforced concrete pillar, the numerical model hereinbefore is used. The middle element on the surface facing the explosive of the No. 1 pillar is selected and the displacement time history curve of the element is obtained. Determine the pressure and impulse corresponding to different damage degree by changing the weight of explosive and the distance from explosion: if the peak displacement of the middle element of the pillar is less than the limit value of the damage degree, adjust the position of the data point in the P-I diagram by increasing the explosive weight or decreasing the distance from explosion. When the displacement is greater than the limit value of the damage criterion, decrease the explosive weight or increase the distance from explosion, and perform the numerical simulation to make the displacement result tend to the limit value. After a large number of repeated trials and calculations, the pressure-impulse points corresponding to the damage degrees are obtained, and the P-I curves corresponding to the different damage degree of the reinforced concrete pillar are fitted.

In Fig. 14, the three P-I curves correspond to the rotation angle of bearing of the pillar of $2^{\circ}, 5^{\circ}$ and $12^{\circ}$. Three P-I curves divide the coordinate system into four parts. In the region between the curve of minor damage and the coordinate axis, the pillar will be slightly damaged. In the region between the curve of minor damage and the curve of moderate damage, the pillar will be moderate damaged. In the region between the curve of moderate damage and the curve of severe damage, the pillar will be severely damaged. In the region above the curve of severe damage, the pillar will destroy or collapse.

Table 11 Failure criteria for different damage degree [21]

\begin{tabular}{lcc}
\hline Degree & $\begin{array}{c}\text { Rotation angle } \\
\text { of bearing }\end{array}$ & $\begin{array}{c}\text { Maximum mid-span horizontal } \\
\text { displacement }(\mathrm{cm})\end{array}$ \\
\hline Minor damage & $0^{\circ} \sim 2^{\circ}$ & $0 \sim 7.6$ \\
Moderate damage & $2^{\circ} \sim 5^{\circ}$ & $7.6 \sim 19.2$ \\
Severe damage & $5^{\circ} \sim 12^{\circ}$ & $19.2 \sim 46.8$ \\
Destroyed & $>12^{\circ}$ & $>46.8$ \\
\hline
\end{tabular}




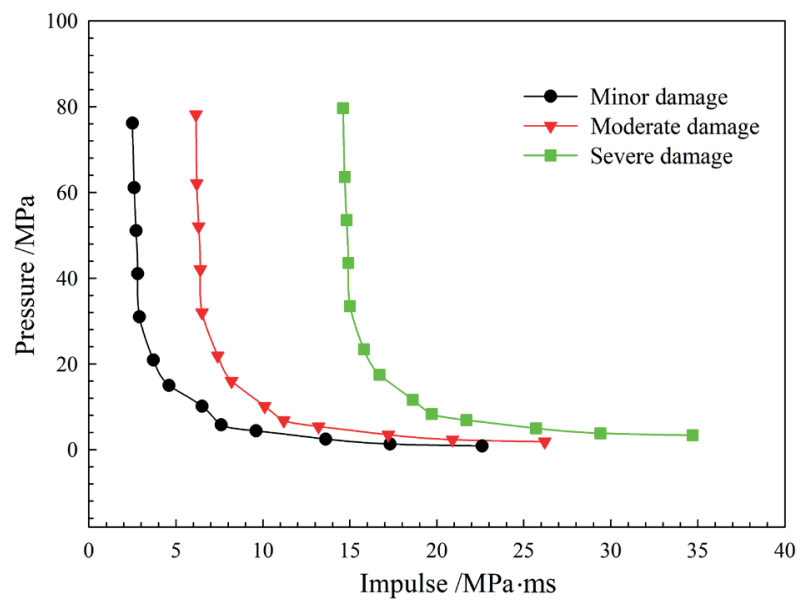

Fig. 14 P-I curves corresponding to the different damage degree

Fit the three P-I curves and get the formula as follows:

$(P-0.66)(I-2.35)^{1.5}=0.08616$,

$(P-1.70)(I-5.95)^{1.5}=0.0887$,

$(P-3.20)(I-14.35)^{1.5}=0.20841$.

For the No. 1 RC pillar, the characteristics of the P-I curve and curve fitting formula are as follows: When the rotation angle of bearing of the pillar are $2^{\circ}, 5^{\circ}$ and $12^{\circ}$, the corresponding pressure asymptotes are $0.66 \mathrm{MPa}, 1.70 \mathrm{MPa}$ and 3.20 MPa, respectively. When the rotation angle of bearing of the pillar are $0^{\circ}, 5^{\circ}$ and $12^{\circ}$, the corresponding impulse asymptotes are $2.35 \mathrm{MPa} \cdot \mathrm{ms}, 5.95 \mathrm{MPa} \cdot \mathrm{ms}$ and 14.35 $\mathrm{MPa} \cdot \mathrm{ms}$, respectively. To put it another way, if the pressure of the blast load is less than $4.9 \mathrm{MPa}, 5.2 \mathrm{MPa}$, and 6.0 MPa, even if the impulse of the blast load is increased indefinitely, there will be no damage above the corresponding damage degree on the pillar. Similarly, if the impulse of the blast load is less than $12.5 \mathrm{MPa} \cdot \mathrm{ms}, 20.5 \mathrm{MPa} \cdot \mathrm{ms}$, and $25.5 \mathrm{MPa} \cdot \mathrm{ms}$, even if the pressure of the blast load is infinitely increased, there will be no damage above the corresponding damage degree on the pillar.

It can be seen from the figure that the curve of the damage of the P-I curve under the combined action of overpressure and impulse is shorter, which indicates that the probability of bending and shear failure of the No.1 pillar is lower than the probability of occurrence of bending failure and shear failure.

\section{Discussion on prevention measures for explosion induced damage}

The objective of the anti-terrorist explosion design of metro stations is to prevent progressive collapse [35] of the overall structure after a partial explosion and to avoid damage to the structural pillar that is difficult to repair under the tolerable explosive load. In view of the accidental explosion that may occur inside the metro station, the following suggestions are put forward based on the analysis and summary of the above research content and conclusions, which provide a reference for the conceptual design of anti-blast protection of the metro station structure.

(1) When designing the metro station structure, the side platform structure can be adopted. The structural pillars are arranged between the two traffic tracks, which effectively increases the distance between the explosion source and the structural pillars, greatly reduces the explosive load on the pillars, and improves the overall anti-blast safety performance of the metro station structure.

(2) The platform slab of a metro station is a typical oneway slab. When designing its structure, deformation joints can be used to divide the overall platform slab into small blocks along the length. When an accidental explosion occurs above a block of the platform, the block can absorb the explosion energy through large deformation, reduce the damage of the reflected shock wave to other structural members, and facilitate the repair after the explosion occurs

(3) The structural pillars and beams of metro stations are the main load-bearing components inside the structure. The cross-sectional area can be appropriately increased or the stirrup configuration form can be improved, such as increasing the diameter of the stirrup and reducing the spacing between the stirrups.

On the other hand, in general, the structure of metro stations is huge, and it is obviously uneconomical to fortify all structural pillars. Moreover, it is also unrealistic for some existing metro stations to anti-blasts re-design and build. Therefore, local anti-blast reinforcement measures are more feasible, so, according to the conclusion of this study, the following preventive measures can be taken for key parts:

(4) The research results in the previous sections show that the corners of the support pillar are weak parts, so the steel jackets can be wrapped around it to reduce the possibility of damage.

(5) The middle part of each section of the pillar may be cracked or damaged due to the high stress and the high overpressure peak of the surface that facing the explosive, so, the pillar surface can be wrapped with foamed aluminum material or high-strength fabrics such as carbon fiber composite materials, glass fiber composite materials, Kevlar, etc. to enhance the explosion resistance of the support pillar [36]. 
(6) It is an economical and practical anti-blasting measure to ensure that the reinforced concrete supporting pillar has a reasonable safety distance by setting up obstacles and billboards.

\section{Conclusions}

In this study, we assumed that a typical metro station was subjected to a terrorist attack, and a $20 \mathrm{~cm} \times 20 \mathrm{~cm} \times 20 \mathrm{~cm}$ explosive package was placed in a typical location (the ground of the platform layer), and then the disaster of an internal explosion was simulated and analyzed. The following conclusions are obtained:

(1) The peak overpressure curve and the positive pressure time curve of the shock wave of explosion air obtained from the numerical simulation results are significantly related to the results of commonly used theoretical formulas, and the correlation coefficient reaches more than 0.9 . This indicates the validity of the numerical simulation model and the reliability of the numerical calculation results.

(2) According to the overpressure criteria and combined with the finite element model established in this paper, the range of different casualty levels of human body on the platform slab during the explosion of $13.04 \mathrm{~kg}$ TNT in the metro station is divided.

\section{References}

[1] Liu, Z., Jiang, N., Sun, J., Xia, Y., Lyu, G. "Influence of tunnel blasting construction on adjacent highway tunnel: A case study in Wuhan, China", International Journal of Protective Structures, 11(3), pp. 283-303, 2020. http://doi.org/10.1177/2041419619888936

[2] Chandra, N., Ganpule, S., Kleinschmit, N. N., Feng, R., Holmberg, A. D., Sundaramurthy, A., Selvan, V., Alai, A. "Evolution of blast wave profiles in simulated air blasts: experiment and computational modeling", Shock Waves, 22, pp. 403-415, 2012. http://doi.org/10.1007/s00193-012-0399-2

[3] Lidner, M., Szcześniak, Z. "Numerical Analysis of Blast Load from Explosive Materials Using Finite Volume Method", Key Engineering Materials, 723, pp. 789-794, 2016. http://doi.org/10.4028/www.scientific.net/KEM.723.789

[4] Tai, Y. S., Chu, T. L., Hu, H. T., Wu, J. Y. "Dynamic response of a reinforced concrete slab subjected to air blast load", Theoretical and Applied Fracture Mechanics, 56(3), pp. 140-147, 2011. http://doi.org/10.1016/j.tafmec.2011.11.002

[5] Feldgun, V. R., Karinski, Y. S., Yankelevsky, D. Z. "The effect of an explosion in a tunnel on a neighboring buried structure", Tunnelling and Underground Space Technology, 44, pp. 42-55, 2014. http://doi.org/10.1016/j.tust.2014.07.006
(3) The peak Mises stress and peak displacement at the corners of the pillar are 1.93 times and 1.33 times higher than that on the surface of the pillar, respectively. Therefore, the corners of the pillar are weak parts that are easily damaged and should be reinforced.

(4) Due to the action of the explosion shock wave, the stress distribution in each parts of the pillar is very uneven, and the overpressure peak of the surface that facing the explosive is larger than the surface that facing away from the explosive. The middle part of each section of the pillar may be cracked or damaged due to the high stress. The P-I curves for three levels of damage of the pillar are obtained.

(5) The numerical simulation method can simulate and predict the nonlinear dynamic response of pillars of metro station under the action of explosion shock wave, and provide an important experience for the safety monitoring and risk assessment of the metro station.

\section{Acknowledgement}

The author(s) disclosed receipt of the following financial support for the research, authorship, and/or publication of this article: The authors acknowledge the financial support from the National Natural Science Foundation of China (Grant No. 41572281 and No. 41807265), and the Natural Science Foundation of Hubei Province of China (Grant No. 2017CFB310).

[6] Zhou, C., Jiang, N., Ping, W., He, R. "Propagation Characteristics of Medium Length Hole Blasting Air Wave in Mining Tunnel", Electronic Journal of Geotechnical Engineering, 18(J), pp. 18671880, 2013. [online] Available at: http://www.ejge.com/2013/ Abs2013.180.htm

[7] Smith, P. D., Mays, G. C., Rose, T. A., Teo, K. G., Roberts, B. J. "Small scale models of complex geometry for blast overpressure assessment", International Journal of Impact Engineering, 12(3), pp. 345-360, 1992.

http://doi.org/10.1016/0734-743X(92)90112-7

[8] Liu, H. "Dynamic Analysis of Subway Structures Under Blast Loading", Geotechnical and Geological Engineering, 27, pp. 699711, 2009.

http://doi.org/10.1007/s10706-009-9269-9

[9] Buonsanti, M., Leonardi, G. "3-D simulation of tunnel structures under blast loading", Archives of Civil and Mechanical Engineering, 13(1), pp. 128-134, 2013.

http://doi.org/10.1016/j.acme.2012.09.002

[10] Yan, Q. S. "Damage Assessment of Subway Station Columns Subjected to Blast Loadings", International Journal of Structural Stability and Dynamics, 18(3), Article number: 1850034, 2018. http://doi.org/10.1142/S0219455418500347 
[11] Pennetier, O., William-Louis, M., Langlet, A. "Numerical and reduced-scale experimental investigation of blast wave shape in underground transportation infrastructure", Process Safety and Environmental Protection, 94, pp. 96-104, 2015. http://doi.org/10.1016/j.psep.2015.01.002

[12] He, W., Chen, J., Guo, J. "Dynamic analysis of subway station subjected to internal blast loading", Journal of Central South University of Technology, 18, pp. 917-924, 2011. http://doi.org/10.1007/s11771-011-0781-8

[13] Tan, X. G., Przekwas, A. J., Gupta, R. K. "Computational modeling of blast wave interaction with a human body and assessment of traumatic brain injury", Shock Waves, 27, pp. 889-904, 2017. http://doi.org/10.1007/s00193-017-0740-x

[14] Sławiński, G., Niezgoda, T., Barnat, W., Wojtkowski, M. "Numerical analysis of the influence of blast wave on human body", Journal of KONES, 20(3), pp. 381-386, 2013. [online] Available at: http://yadda.icm.edu.pl/yadda/element/bwmeta1.element.baztech45a4c010-6d41-447d-8630-7da3cee47f88

[15] Ma, T., Xu, X., Ning, J. "Research on propagation laws of explosion shock wave inside metro station", Journal of Loss Prevention in the Process Industries, 46, pp. 54-68, 2017. http://doi.org/10.1016/j.jlp.2017.01.009

[16] Yang, W. "Wuhan Metro operates 237 kilometers, with an average daily passenger traffic of 3.05 million times", [online] Available at: http://hb.ifeng.com/a/20180412/6496922_0.shtml [Accessed: 27 September 2020] (in Chinese)

[17] Tao, L., Li, S. "Study on Transfer Schemes between Liyuan Station and OCT Branch Line of Wuhan Metro", Tunnel Construction, 35(6), pp. 565-570, 2015. (in Chinese) http://doi.org/10.3973/j.issn.1672-741X.2015.06.012

[18] Deeks, A. J., Randolph, M. F. "Axisymmetric tTime-Domain Transmitting Boundaries", Journal of Engineering Mechanics, 120(1), pp. 25-42, 1994. http://doi.org/10.1061/(ASCE)0733-9399(1994)120:1(25)

[19] Hallquist, J. O. "LS-DYNA Keyword User's Manual, Version: 970", Livermore Software Technology Corporation, Livermore, CA, USA. [online] Available at: https://www.scienceopen.com/document?vid=1828d561-f3d9-459d-bf63-fe19313933e2 [Accessed: 27 September 2020]

[20] Tu, Z., Lu, Y. "Evaluation of typical concrete material models used in hydrocodes for high dynamic response simulations", International Journal of Impact Engineering, 36(1), pp. 132-146, 2009. http://doi.org/10.1016/j.ijimpeng.2007.12.010

[21] US Department Of The Army "TM5-1300 Structures to Resist the Effects of Accidental Explosion", [pdf], Picatinny Arsenal, NJ, USA, 1990. Available at: https://www.wbdg.org/FFC/DOD/UFC/ ARCHIVES/ufc_3_340_02_2008.pdf[Accessed: 27 September 2020]

[22] Xu, S., Zhang, X., Pan, F., Zhang, J. "Analysis of Energy Test Methods for Industrial Explosives", Explosive Materials, 42(1), pp. 18-21, 2013. (in Chinese) http://doi.org/10.3969/j.issn.1001-8352.2013.01.005

[23] Borrvall, T., Riedel, W. "The RHT Concrete Model in LS-DYNA", [pdf] presented at 8th European LS-DYNA Users Conference, Strasbourg, France, May, 23-24, 2011. Available at: https://www. dynalook.com/conferences/8th-european-ls-dyna-conference/session-12/Session12_Paper1.pdf
[24] Deng, R., Jin, X., Chen, X., Du, X., Shen, J., Li, Z. "Numerical Simulation for the Damage Effect of Bridge Subjected to Blast Wave", Journal of Shanghai Jiaotong University, 42(11), pp. 19271930, 2008. (in Chinese) [online] Available at: http://xuebao.sjtu. edu.cn/CN/Y2008/V42/I11/1927

[25] Henrych, J. "The Dynamics of Explosion and Its Use" (Reviewed by Abrahamson, G. R.), Journal of Applied Mechanics, 47(1), p. 218, 1980. https://oi.org/10.1115/1.3153619

[26] Sadovskii, M. A., Adushkin, V. V., Rodionov, V. N. "Modeling of Large Ejection Explosions", Soviet Physics Doklady, 11, p. 293, 1966.

[27] Brode, H. L. "Blast Wave from a Spherical Charge", Physics of Fluids, 2, p. 217, 1959 http://doi.org/10.1063/1.1705911

[28] Sedgwick, P. "Pearson's correlation coefficient", BMJ, 345, Article number: e4483, 2012. http://doi.org/10.1136/bmj.e4483

[29] Gruss, E. "A Correction for Primary Blast Injury Criteria", Journal of Trauma and Acute Care Surgery, 60(6), pp. 1284-1289, 2006. http://doi.org/10.1097/01.ta.0000220015.21948.ec

[30] Brode, H. L. "Review of Nuclear Weapons Effects", Annual Review of Nuclear Science, 18(1), pp. 153-202, 2005. http://doi.org/10.1146/annurev.ns.18.120168.001101

[31] Zheng, L. "Safety distance for persons under blast air-shock", Explosion and Shock Waves, 10(2), pp. 135-144, 1990. [online] Available at: http://www.bzycj.cn/article/1990/2?pageType=en (in Chinese)

[32] Yan, Q., Liu, J., Wu, J. "Estimation of casualty areas in subway station subjected to terrorist bomb", Gongcheng Lixue/Engineering Mechanics, 29(2), pp. 81-88, 2012. (in Chinese) [online] Available at: https://www.ixueshu.com/document/0c25ea62490640e5f362c705bd3561f7318947a18e7f9386.htm

[33] Ramajeyathilagam, K., Vendhan, C. P., Rao, V. B. "Non-linear transient dynamic response of rectangular plates under shock loading", International Journal of Impact Engineering, 24(10), pp. 999-1015, 2000. http://doi.org/10.1016/S0734-743X(00)00018-X

[34] Luo, Z., Chen, J., Xie, C., Wang, W., Liu, X. "Mechanism of impact-induced damage of main chute and its experimental validation", Rock and Soil Mechanics, 36(6), pp. 1744-1752, 2015. (in Chinese) http://doi.org/10.16285/j.rsm.2015.06.028

[35] Ellingwood, B. R., Leyendecker, E. V. "Approaches for Design against Progressive Collapse", Journal of the Structural Division, 104(3), pp. 413-423, 1978.

[36] Morrill, K. B., Malvar, L. J., Crawford, J. E., Ferritto, J. M. "Blast Resistant Design and Retrofit of Reinforced Concrete Columns and Walls", presented at Structures Congress 2004, Nashville, TN, USA, May, 22-26, 2004.

https:/ascelibrary.org/doi/abs/10.1061/40700(2004)154 